\title{
Outcome of urethral strictures treated by endoscopic urethrotomy and urethroplasty
}

\author{
Javier Tinaut-Ranera, MD; $;^{*}$ Miguel Ángel Arrabal-Polo, MD; ${ }^{*}$ Sergio Merino-Salas, MD; ${ }^{*}$ Mercedes Nogueras- \\ Ocaña, MD; ${ }^{*}$ Víctor Manuel López-León, MD;, Francisco Palao-Yago, MD;" Miguel Arrabal-Martín, MD; \\ Clara Lahoz-García, MD; ${ }^{*}$ Miguel Alaminos, MD; ${ }^{\dagger}$ Armando Zuluaga-Gomez, MD*
}

*Urology Department, San Cecilio University Hospital, Granada, Spain; HHistology Department, Faculty of Medicine, Granada, Spain

Cite as: Can Urol Assoc J 2014;8(1-2):e16-9. http://dx.doi.org/10.5489/cuaj.1407

Published online January 14, 2014.

\section{Abstract}

Introduction: We analyze the outcomes of patients with urethral stricture who underwent surgical treatment within the past 5 years. Methods: This is a retrospective study of male patients who underwent surgery for urethral stricture at our service from January 2008 to June 2012. We analyzed the comorbidities, type, length and location of the stricture and the surgical treatment outcome after endoscopic urethrotomy, urethroplasty or both.

Results: In total, 45 patients with a mean age of $53.7 \pm 16.7$ years underwent surgical treatment for urethral stricture. Six months after surgery, $46.7 \%$ of the patients had a maximum urinary flow greater than $15 \mathrm{~mL} / \mathrm{s}$, whereas $87.3 \%$ of the patients exhibited no stricture by urethrography after the treatment. The success rate in the patients undergoing urethrotomy was $47.8 \%$ versus $86.4 \%$ in those undergoing urethroplasty $(p=0.01)$. Twenty percent of the patients in whom the initial urethrotomy had failed subsequently underwent urethroplasty, thereby increasing the treatment success. Conclusion: In most cases, the treatment of choice for urethral stricture should be urethroplasty. Previous treatment with urethrotomy does not appear to produce adverse effects that affect the outcome of a urethroplasty if urethrotomy failed, so urethrotomy may be indicated in patients with short strictures or in patients at high surgical risk.

\section{Introduction}

Male urethral stricture has a high prevalence. It affects $15 \%$ to $20 \%$ of male adults at any time of life, ${ }^{1}$ although other authors reported a prevalence between $0.6 \%$ and $1.4 \% .^{2,3}$ The causes of urethral stricture are varied, but idiopathic/ unknown and iatrogenic factors are generally considered the most frequent causes. ${ }^{4,5}$ The diagnosis of urethral stricture is usually established by uroflowmetry and serial voiding ure- thrography or only retrograde urethrography, which are used to assess the degree, length and level of urethral stricture. ${ }^{6,7}$ Once the diagnosis is confirmed, the question is about the type of surgery, which will depend on the location and length of the stricture. A wide variety of techniques have been described for the treatment of the anterior urethra, including dilations, urethrotomy, end-to-end urethroplasty, graft urethroplasty, flap urethroplasty and two-stage urethroplasty; success rates depend on the study and the type of treatment. ${ }^{8,9}$ Surgical treatment of the posterior urethra (including bulbar urethra) is more standardized and is generally related to the length of the stricture. A urethrotomy is preferred if the length is less than $1 \mathrm{~cm}$, and a urethroplasty is indicated when the length is greater than $1 \mathrm{~cm} .{ }^{10,11}$ The results obtained after endoscopic treatment or open surgery vary depending on the series and various factors such as the location or size of the stricture or etiology; however, these procedures have better outcomes in patients treated with urethroplasty. ${ }^{12,13}$

The objective of this study was to analyze the results obtained in our hospital during the last 5 years in male patients who underwent surgical treatment for urethral stricture by different surgical techniques.

\section{Methods}

\section{Study subjects}

We conducted a retrospective study analyzing the results obtained after treatment of urethral stricture in 45 patients between January 2008 and July 2012 in the Urology Department at the San Cecilio University Hospital of Granada, Spain. Study variables include patient age and concomitant diseases. We assessed the characteristics of the stricture using the following variables: cause of the stricture, 
location of the stricture, length of the stricture (serial voiding urethrography or retrograde uretrography), maximum urinary flow before surgery, maximum urinary flow 6 months after surgery, and functional results with serial voiding urethrography 6 months after surgery.

\section{Statistical analysis}

The Shapiro-Wilk test or the D'Agostino-Pearson omnibus test was applied to verify that the analyzed quantitative variables followed a normal distribution. A logarithmic transformation was performed on the variables that did not follow the normal distribution. The profile of the study population was described. The results of the qualitative variables were expressed as percentages, and the continuous variables were expressed as means and standard deviations. The chi-square test was used to compare the proportions between groups, and if it failed to satisfy the conditions of validity, then the Fisher exact test was applied. If the conditions for application of the parametric test were not fulfilled, then the nonparametric Kruskal-Wallis test for $\mathrm{K}$ contrast medium and the Mann-Whitney $U$ test were applied. The level of statistical significance was $p<0.05$.

\section{Results}

Between January 2008 and July 2012, 45 men with a diagnosis of urethral stricture underwent surgical treatment; patients had a mean age of $53.7 \pm 16.7$ years (Table 1 ). The causes of the stricture were trauma in 2 cases $(4.4 \%)$, infection in 2 cases $(4.4 \%)$, congenital disorders in 5 cases $(11.1 \%)$, bladder catheterization in 5 cases $(11.1 \%)$, prostatic/bladder transurethral resection (TUR) in 10 cases $(22.2 \%)$, balanitis in 1 case $(2.2 \%)$ and unknown in 20 cases $(44.4 \%)$. Of the strictures, $53.3 \%$ were located in the bulbar urethra, 20\% were located in the urethral meatus, $8.9 \%$ were located in the membranous urethra, $8.9 \%$ were located in the proximal penile urethra, $6.7 \%$ were located in the distal penile urethra and $2.2 \%$ affected the entire urethra. The mean length of the stricture was $1.85 \pm 2.1 \mathrm{~cm}$. The maximum urinary flow before surgery was $5.5 \pm 2.2 \mathrm{~mL} / \mathrm{s}$. The maximum urinary flow at 6 months after surgery was $15.1 \pm 9.1 \mathrm{~mL} / \mathrm{s}$. Regarding the type of surgery performed, $31.1 \%$ of patients underwent internal urethrotomy, $48.9 \%$ underwent urethro-

\begin{tabular}{lc}
$\begin{array}{l}\text { Table 1. Presence of other comorbidities present at the } \\
\text { time of surgical treatment of urethral stricture }\end{array}$ \\
\hline \multicolumn{2}{c}{ No. patients (n=45) } \\
\hline Age (years) & $53.7 \pm 16.7$ \\
Diabetes mellitus & $20 \%$ \\
Smoking & $26.7 \%$ \\
Chronic obstructive pulmonary disease & $24.4 \%$ \\
Cardiovascular disease & $13.3 \%$
\end{tabular}

plasty and $20 \%$ underwent urethrotomy followed by urethroplasty. Of the patients subjected to urethroplasty, 32.3\% underwent meatoplasty (repairing stricture of meatus and navicular fossa), $41.9 \%$ underwent end-to-end urethroplasty, $12.9 \%$ received a penile skin flap, $6.5 \%$ received a scrotal flap, $3.2 \%$ received a preputial flap and $3.2 \%$ underwent a two-stage surgery without receiving a graft.

The overall results of the surgery were analyzed 6 months postoperatively by performing flowmetry and serial voiding urethrography (median of 21 months; range of follow-up 6-48 months). We present the results of a 6-month follow-up in all patients; in patients with a greater follow-up, the results did not change. If uroflow success was considered a maximum flow greater than $15 \mathrm{~mL} / \mathrm{s}$ after treatment, then $46.7 \%$ of patients had a peak flow that was higher than $15 \mathrm{~mL} / \mathrm{s}$, and $52.3 \%$ had a peak flow that was less than $15 \mathrm{~mL} / \mathrm{s}$. However, in $87.3 \%$ of patients, recurrence of stricture after surgery was not observed upon a voiding urethrography, while recurrence of stricture was observed in the remaining $12.7 \%$. The clinical results were superior to those reflected after performing flowmetry.

In patients who underwent urethrotomy, the procedure was performed a mean of $1.32 \pm 0.94$ times; in $20 \%$ of the subjects, the treatment included urethroplasty due to the poor results of the previous endoscopic treatment. Analysis of the studied parameters revealed that the length of the stricture was the only factor that influenced sole treatment or treatment with urethrotomy and subsequent urethroplasty (Table 2).

When the surgical outcomes were compared between the patients undergoing internal urethrotomy versus urethroplasty, the success of urethrotomy was $47.8 \%$ compared with $86.4 \%$ for urethroplasty $(p=0.01$ ) (Table 3 ).

We observed no differences in the other clinical parameters (the previously diagnosed diseases are listed in Table 1 ) or in the results that were obtained after surgery in the

Table 2. Differences between the different types of treatment performed

\begin{tabular}{|c|c|c|c|c|}
\hline & Urethrotomy & Urethoplasty & Urethrotomy-urethroplasty & $p$ value \\
\hline No. patients & 14 & 22 & 9 & - \\
\hline Age (years) & $57.9 \pm 17.4$ & $52.5 \pm 16.6$ & $50.3 \pm 16.2$ & 0.51 \\
\hline Stricture length & $1.1 \pm 0.5$ & $1.6 \pm 1.6$ & $3.4 \pm 3.1$ & 0.04 \\
\hline Qmax pre-surgery & $5.1 \pm 1.9$ & $6.4 \pm 2.1$ & $4.8 \pm 2.4$ & 0.16 \\
\hline Qmax post-surgery & $13.5 \pm 8.1$ & $14.7 \pm 8.8$ & $18.9 \pm 10.8$ & 0.45 \\
\hline
\end{tabular}




\begin{tabular}{|c|c|c|}
\hline & Urethrotomy & Urethroplasty \\
\hline Success & $47.8 \%$ & $86.4 \%$ \\
\hline Fail & $52.2 \%$ & $13.6 \%$ \\
\hline
\end{tabular}

Failure after urethrotomy occurred in $20 \%$ of patients who then underwent urethroplasty. No differences were observed between success of urethroplasty vs. urethrotomy followed urethroplasty $(p=0.01)$.

different treatment modalities analyzed, after comparing the patients with postoperative peak flows higher than $15 \mathrm{~mL} / \mathrm{s}$ to the patients with postoperative peak flows lower than $15 \mathrm{~mL} / \mathrm{s}$. Moreover, upon postoperative urethrography, no differences in the above parameters were found in patients without stricture compared with patients who did have stricture. Significant peak-flow differences $(19.1 \pm 8.8$ vs. $7.9 \pm 2.4 ; p<0.0001$ ) only existed between patients who exhibited no stricture upon urethrography and the patients who did have stricture after the surgery.

\section{Discussion}

The surgical treatment of urethral stricture remains controversial, although most practitioners consider urethroplasty the gold standard. ${ }^{14}$ Others consider internal urethrotomy and even urethral dilations as valid and important treatment options..$^{13,15}$ The results obtained in our study make us favour urethroplasty as the initial treatment when the length of the stricture is $1.5 \mathrm{~cm}$, and we definitely recommend urethroplasty if the length is greater than $3 \mathrm{~cm}$ or in cases where internal urethrotomy is not indicated and treatment failure occurs - as was observed in our patients who subsequently had to undergo urethroplasty. It should be better to study the results comparing different length strictures (shorter than $1.5 \mathrm{~cm}$ and longer than $3 \mathrm{~cm}$ ), but the number of patients and characteristics of strictures do not permit us to perform this analysis. However, pretreatment with urethrotomy does not influence the subsequent results after performing urethroplasty ${ }^{16}$ and may thus be an initially less invasive treatment, based on the surgical risks and patient preferences. However, we must emphasize that over the years, the results of urethrotomy have been worse than those of urethroplasty. ${ }^{17}$ Many patients require several endoscopic treatments to achieve improved quality of life, functionality and lower-urinary-tract function; this phenomenon occurred in our study, in which the endoscopic technique was performed (on average) more than once per patient. Clinical factors are not the only determinants that lead us to prefer one technique over the other for treating urethral stricture; economic and geographical factors also affect the decision of whether to perform internal urethrotomy or urethroplasty. In terms of economic factors and cost-effectiveness, internal urethrotomy is superior to urethroplasty as long as the stricture does not exceed $2 \mathrm{~cm}$ in length. Therefore, it is appropriate to choose internal urethrotomy over urethroplasty in patients who meet this condition. ${ }^{18}$ Regarding the geographical distribution, in this case, within the United States, it appears that there is a significant disparity in the performance of urethroplasty by state, ranging from $0 \%$ to $17 \%$. Generally, 1 urethroplasty is performed for every 17 urethrotomies or dilations. The states where more urethroplasties are performed either have more residents in their centres or have the procedures performed by young urologists. ${ }^{19}$ We agree with Burks and colleagues ${ }^{19}$ that it is necessary to implement a certification and quality program that allows for the recycling of older urologists and that encourages more urethroplasties than urethrotomies, with the aim of improving the functional results.

Conducting a urethroplasty instead of a urethrotomy offers the urologist greater leeway in the surgical treatment by allowing for the performance of different techniques, depending on the type, location and length of the stricture. In our study, the most used technique was urethroplasty with end-to-end anastomosis, although we also performed scrotal flaps or preputial grafts. In contrast with the findings observed by other authors, ${ }^{20}$ the presence of concomitant diseases, such as diabetes mellitus, smoking or cardiovascular disease, had no influence on the results obtained after treatment, although the short follow-up and small number of patients with these pathologies can influence these results. Overall, performing urethroplasty either by end-to-end anastomosis or by graft or flap placement has a success rate of $85 \%$ to $95 \%,{ }^{21,22}$ which is similar to the results obtained in our study. Surgical treatment failure after urethroplasty may be related to early bladder catheter removal or excessive fibrosis after the surgery. ${ }^{23}$ Performing urethroplasty to treat urethral stricture not only has advantages over endoscopic urethrotomy but also allows for the introduction of different techniques and variations, which are not possible with urethrotomy (although different techniques of urethrotomy can be used with different types of materials like laser, cold cut or electric cut). Moreover, urethroplasty has facilitated the recent implementation of tissue engineering with inorganic matrices for surgery, ${ }^{24}$ as well as organic matrices that are enriched with cells of various origins. ${ }^{25}$

The limitations of our work include the small number of patients and the retrospective nature of the study; the results should be confirmed in a prospective study with similar patient characteristics. Also, the small number of patients does not allow us to perform an analysis of subclassifications of patients by comorbidities or length of strictures.

\section{Conclusion}

We propose that urethroplasty is ideal for urethral stricture with a length greater than $1.5 \mathrm{~cm}$. In selected cases, endo- 
scopic urethrotomy may be an option that does not worsen the outcome after a subsequent urethroplasty.

Competing interests: Dr. Tinaut-Ranera, Dr. Arrabal-Polo, Dr. Merino-Salas, Dr. Nogueras-Ocaña, Dr. López-León, Dr. Palao-Yago, Dr. Arrabal-Martín, Dr. Lahoz-García, Dr. Alaminos and Dr. Zuluaga-Gomez all declare no competing financial or personal interests.

This paper has been peer-reviewed.

\section{References}

1. Mundy AR, Andrich DE. Urethral strictures. BJU Int 2010;107:6-26. http://dx.doi.org/10.1111/j.1464410X.2010.09800.X

2. Santucci RA, Joyce GF, Wise M. Male urethral stricture disease. J Urol 2007;177:1667-74. http:// dx.doi.org/10.1016/i.juro.2007.01.041

3. Anger JT, Santucci R, Grossberg AL, et al. The morbidity of urethral stricture disease among male medicare beneficiaries. BMC Urol 2010;10:3. http://dx.doi.org/10.1186/1471-2490-10-3

4. Fenton AS, Morey AF, Aviles R, et al. Anterior urethral strictures: Etiology and characteristics. Urology 2005;65:1055-8. http://dx.doi.org/10.1016/j.urology.2004.12.018

5. Lumen $\mathrm{N}$, Hoebeke $\mathrm{P}$, Willemsen $\mathrm{P}$, et al. Etiology of urethral stricture disease in the 21 st century. J Urol 2009;182:983-7. http://dx.doi.org/10.1016/i.juro.2009.05.023

6. Morey AF, McAninch JW, Duckett CP, et al. American Urological Association symptom index in the assessment of urethroplasty outcomes. J Urol 1998;159:1192-4. http://dx.doi.org/10.1016/S00225347(01)63552-3

7. Heyns CF, Marais DC. Prospective evaluation of the American Urological Association symptom index and peak urinary flow rate for the follow-up of men with known urethral stricture disease. J Urol 2002;168:2051-4. http://dx.doi.org/10.1016/S0022-5347(05)64293-0

8. Singh 0, Gupta SS, Arvind NK. Anterior urethral strictures: A brief review of the current surgical treatment Urol Int 2011;86:1-10. http://dx.doi.org/10.1159/000319501

9. Barbagli $G$, Sansalone $S$, Diinovic $R$, et al. Current controversies in reconstructive surgery of the anterior urethra: A clinical overview. Int Braz J Urol 2012;38:307-16. http://dx.doi.org/10.1590/S1677. 55382012000300003
10. Hosseini SJ, Kaviani A, Varzinia AR. Internal urethrotomy combined with antegrade flexible cystoscopy for management of obliterative urethral stricture. Urol J 2008;5:184-7.

11. Santucci RA, Mario LA, McAninch JW. Anastomotic urethroplasty for bulbar urethral stricture: Analysis of 168 patients. J Urol 2002;167:1715-9. http://dx.doi.org/10.1016/S0022-5347(05)65184-1

12. Santucci RA, McAninch JW, Mario LA, et al. Urethroplasty in patients older than 65 years: Indications, results, outcomes and suggested treatment modifications. J Urol 2004;172:201-3. http://dx.doi. org/10.1097/01.ju.0000128810.86535.be

13. Veeratterapillay R, Pickard RS. Long-term effect of urethral dilatation and internal urethrotomy for urethral strictures. Curr Opin Urol 2012;22:467-73. http://dx.doi.org/10.1097/MOU.0b013e32835621a2

14. Andrich DE, Mundy AR. What is the best technique for urethroplasty? Eur Urol 2008;54:1031-41. http:// dx.doi.org/10.1016/j.eururo.2008.07.052

15. Heyns CF, Van der Merwe J, Basson J, et al. Treatment of male urethral strictures - possible reasons for the use of repeated dilatation or internal urethrotomy rather than urethroplasty. S Afr J Surg 2012;50:82-7.

16. Barbagli $G$, Palminteri E, Lazzeri $M$, et al. Long-term outcome of urethroplasty after failed urethrotomy versus primary repair. J Urol 2001;165:1918-9. http://dx.doi.org/10.1016/S0022-5347(05)66242-8

17. Santucci R, Eisenberg L. Urethrotomy has a much lower success rate than previously reported. J Urol 2010;183:1859-62. http://dx.doi.org/10.1016/i.juro.2010.01.020

18. Wessells H. Cost-effective approach to short bulbar urethral strictures supports single internal urethrotomy before urethroplasty. J Urol 2009;181:954-5.

19. Burks FN, Salmon SA, Smith AC, et al. Urethroplasty: A geographic disparity in care. J Urol 2012;187:21247. http://dx.doi.org/10.1016/i.juro.2012.01.078

20. Breyer BN, McAninch JW, Whitson JM, et al. Multivariate analysis of risk factors for long-term urethroplasty outcome. J Urol 2010;183:613-7. http://dx.doi.org/10.1016/i.juro.2009.10.018

21. Lumen N, Hoebeke P, Oosterlinck W. Urethroplasty for urethral strictures: Quality assessment of an inhome algorithm. Int J Urol 2010;17:167-74. http://dx.doi.org/10.1111/j.1442-2042.2009.02435.x

22. Micheli E, Ranieri A, Peracchia G, et al. End-to-end urethroplasty: Long-term results. BJU Int 2002;90:6871. http://dx.doi.org/10.1046/i.1464-410X.2002.02832.x

23. Koraitim MM. Unsuccessful outcomes after posterior urethroplasty: Definition, diagnosis, and treatment. Urology 2012;1168-72. http://dx.doi.org/10.1016/i.urology.2011.11.078

24. Selim M, Bullock AJ, Blackwood KA, et al. Developing biodegradable scaffolds for tissue engineering of the urethra. BJU Int 2010;107:296-302. http://dx.doi.org/10.1111/i.1464-410X.2010.09310.x

25. Raya Rivera A, Esquiliano DR, Yoo JJ, et al. Tissue-engineered autologous urethras for patients who need reconstruction: An observational study. Lancet 2011;377:1175-82. http://dx.doi.org/10.1016/ S0140-6736(10)62354-9

Correspondence: Dr. Miguel Angel Arrabal-Polo Camino de Ronda Street, 143, 4F, Granada,. Spain 18003; arrabalp29@gmail.com 